\title{
Direct Observation of the Behaviour of Females with Rett Syndrome
}

\author{
Rina Cianfaglione ${ }^{1}$ - Andrea Meek ${ }^{1}$. \\ Angus Clarke $^{2} \cdot$ Michael Kerr $^{1}$. \\ Richard P. Hastings ${ }^{3}$ - David Felce ${ }^{1}$
}

(C) The Author(s) 2016. This article is published with open access at Springerlink.com

\begin{abstract}
The aim was to observe the behaviour of a sample of females with RTT and explore how it was organized in relation to environmental events. Ten participants, all with a less severe form of classic $(n=9)$ or atypical $(n=1)$ Rett syndrome (RTT), were filmed at home and at school or day centre. Analysis used real-time data capture software. Observational categories distinguished engagement in social and non-social pursuits, hand stereotypies, self-injury and the receipt of attention from a parent, teacher or carer. Associations between participant behaviour and intake variables and receipt of
\end{abstract}

David Felce

felce@cf.ac.uk

Rina Cianfaglione

rinacianf@yahoo.it

Andrea Meek

meek@cardiff.ac.uk

Angus Clarke

ClarkeAJ@cardiff.ac.uk

Michael Kerr

KerrMP@cardiff.ac.uk

Richard P. Hastings

R.Hastings@warwick.ac.uk

1 Welsh Centre for Learning Disabilities, Institute of Psychological Medicine and Clinical

Neurosciences, Cardiff University, 2nd floor Hadyn Ellis Building, Maindy Road, Cardiff, Wales CF24 4HQ, UK

2 Institute of Cancer \& Genetics, Institute of Medical Genetics Building, Cardiff University, Heath Park, Cardiff CF14 4XN, UK

3 Centre for Educational Development Appraisal and Research, University of Warwick, Coventry CV4 7AL, UK 
attention were explored. Concurrent and lagged conditional probabilities between behavioural categories and receipt of attention were calculated. Receipt of adult attention was high. Engagement in activity using the hands was associated with a less severe condition and greater developmental age. Engagement in activity, whether using the hands or not, and social engagement were positively associated with receipt of support. The extent of hand stereotypies varied greatly across participants but was independent of environmental events. Six participants self-injured. There was some evidence that self-injury was related to adult attention. Participants appeared to experience a carer and attention rich environment and their levels of engagement seemed high as a result. As in the more general literature, engagement in activity was related to personal development and to social support. Self-injury contrasted with hand stereotypies in having possible environmental function.

Keywords Intellectual disabilities · Rett syndrome - observation of behaviour activity · self-injury

\section{Introduction}

Rett syndrome (RTT) affects almost exclusively females, with an incidence of up to one in every 10,000 live female births. Its cause is most often a mutation in the methyl-CpG binding protein-2 (MECP2) gene, located on the X chromosome at Xq28 (Amir et al. 1999). It is characterised by a period of regression in early childhood, accompanied by loss of purposeful hand skills and language and the development of stereotypic hand movements. This is followed by stabilization and usually ongoing profound intellectual disability. The presence of certain behavioural features in the main or supportive diagnostic criteria (Neul et al. 2010) suggests that RTT syndrome has a definable behavioural phenotype (Cianfaglione et al. 2015a; Mount et al. 2001, 2003). Table 1 lists behaviours, or behavioural signs of possible autonomic disorder such as hyperventilation or breath holding, that are mentioned as occurring either frequently or fairly frequently in six surveys of RTT. Hand stereotypies appear to be pervasive when assessed. Teeth grinding, sleeping difficulties and night-time laughing, screaming, anxiety or inappropriate fear, problems in mood regulation, breathing abnormalities and self-injury may also be expected in the majority or substantial minority.

The extent to which environmental variables may account for behaviour in females with RTT remains largely unexplored as few studies have involved systematic observation of their behaviour in relation to their surroundings. A number of single case studies have explored the functionality of self-injury and hand stereotypies. Oliver et al. (1993) found that the function of the self-injury of a child with RTT was to terminate social contact, whereas Iwata et al. (1986) concluded that the hand biting of two individuals was independent of environmental circumstances and appeared to be selfstimulatory. Wehmeyer et al. (1993); Roane et al. (2001) and Wales et al. (2004) conducted functional assessments of hand stereotypies. All but one analysis suggested that occurrence was at a high rate and unaffected by environmental conditions.

The aims of this study were to add to and broaden the focus of observational research on RTT by exploring how the behaviour of a sample of females with RTT with a confirmed $M E C P 2$ mutation was organized in relation to environmental events. 
Table 1 Behavioural commonalities between surveys of RTT syndrome

\begin{tabular}{|c|c|c|c|c|c|c|}
\hline \multirow{2}{*}{$\begin{array}{l}\text { Behavioural } \\
\text { characteristic }\end{array}$} & \multicolumn{6}{|c|}{ Percentage of sample with characteristic } \\
\hline & $\begin{array}{l}\text { Coleman } \\
\text { et al. }(1988) \\
(N=63)\end{array}$ & $\begin{array}{l}\text { Sansom et al. } \\
(1993) \\
(N=107)\end{array}$ & $\begin{array}{l}\text { Mount et al. } \\
(2001) \\
(N=38)\end{array}$ & $\begin{array}{l}\text { Cass et al. } \\
(2003) \\
(N=87)\end{array}$ & $\begin{array}{l}\text { Halbach } \\
\text { et al. }(2008) \\
(N=53)\end{array}$ & $\begin{array}{l}\text { Cianfaglione } \\
\text { et al. }(2015 \mathrm{a}) \\
(N=91)\end{array}$ \\
\hline $\begin{array}{l}\text { Hand } \\
\text { stereotypies }\end{array}$ & 100 & - & 100 & 97 & - & 99 \\
\hline Teeth grinding & 95 & - & 37 & - & - & 58 \\
\hline Screaming & 84 & 48 (night) & - & - & 39 (night) & 44 \\
\hline $\begin{array}{l}\text { Night unrest/ } \\
\text { laughing }\end{array}$ & 83 & 84 & 21 & - & 77 & 64 \\
\hline $\begin{array}{l}\text { Anxiety/ } \\
\text { Inappropriate } \\
\text { fear }\end{array}$ & 75 & 75 & - & - & 68 & 73 \\
\hline $\begin{array}{l}\text { Low } \\
\text { mood } / \mathrm{mood} \\
\text { changes }\end{array}$ & - & 70 & - & - & 66 & 77 \\
\hline Hyperventilation & 63 & 32 & 84 & 60 & 39 & 63 \\
\hline Breath hold & 57 & - & 37 & 41 & 73 & 77 \\
\hline Self-injury & 49 & 48 & - & 73 & - & 28 \\
\hline
\end{tabular}

- Behavioural characteristic not included in the survey

In particular, as functional hand use is lost in RTT, one objective was to assess the extent of constructive activity that individuals engaged in and the extent to which such engagement relied on social support. A second objective was to examine how seemingly characteristic or socially significant behaviours such as hand stereotypies or selfinjury occurred within the sequence of behaviour and whether they had any discernable environmental antecedents or consequences.

\section{Methods}

\section{Sampling and Participant Characteristics}

Before commencing the study, ethical approval was granted by the NHS Research Ethics Committee for Wales (Application number: 09/MRE09/50). In a prior stage, a national sample of 91 females with RTT had been recruited by contacting families known to the on-going British Isle Rett Syndrome Survey database (Cianfaglione et al. $2015 \mathrm{~b}$ ). The ages of sample members ranged from 4 to 47 years with a mean of 20.5 years: 43 were children and 48 adults. Seventy-one $(78.0 \%)$ were known to be $M E C P 2$ positive. Invitation letters to participate in the direct observational study were sent to 25 of these 71 families and 16 agreed to take part. However, due to the practicalities of travel and constraints on research time, only 11 were visited. Nine had diagnoses of classic RTT, one of atypical RTT and one of MECP2 related disorder. This last person has subsequently been excluded but we have chosen to include the 
individual with atypical RTT, although we have taken care to discuss her results separately from those of the other nine participants with classic RTT. She was categorised as atypical as a regression in language was not noted because she had no babble and did not speak.

The characteristics of the 10 participants are set out in Table 2. Five were children, one an adolescent and four were adults. Their median age was 12.5 years (range 5-32 years). Median developmental age, as measured by the Vineland Adaptive Behavior Scale - Survey Form (Sparrow et al. 1984 see below), was 11.0 months (range 8-15 months). One person could walk unsupported. The ability to walk was impaired in seven of the participants and never acquired in the remaining two. Hand use was reduced in four and lost in six. Speech was lost in eight and never acquired in one. Post-stabilisation, the one participant (P1) with atypical RTT had gained a few words. All were reported to have hand stereotypies. All had a mild/less severe clinical phenotype as assessed by the Simplified Severity Score (Smeets et al. 2009 - see below).

Table 2 Participant characteristics

\begin{tabular}{|c|c|c|c|c|c|c|}
\hline $\begin{array}{l}\text { Partic- } \\
\text { ipant }\end{array}$ & $\begin{array}{l}\text { Chronological age } \\
\text { (years) }\end{array}$ & $\begin{array}{l}\text { Developmental age } \\
\text { (months)* }\end{array}$ & Diagnosis & $\begin{array}{l}M E C P 2 \\
\text { mutation }\end{array}$ & Mobility & $\begin{array}{l}\text { Severity } \\
\text { Score** }\end{array}$ \\
\hline \multicolumn{7}{|c|}{ Children } \\
\hline $\mathrm{P} 1$ & $5 \mathrm{yrs}$ & 13 months & $\begin{array}{l}\text { Atypical } \\
\text { RTT }\end{array}$ & c.116delGA & $\begin{array}{l}\text { Never } \\
\text { Acquired }\end{array}$ & 9 \\
\hline $\mathrm{P} 2$ & 5 yrs & 8 months & $\begin{array}{r}\text { Classic } \\
\text { RTT }\end{array}$ & $\mathrm{R} 294 \mathrm{X}$ & Impaired & 6 \\
\hline P3 & $8 \mathrm{yrs}$ & Not Available & $\begin{array}{r}\text { Classic } \\
\text { RTT }\end{array}$ & $\mathrm{R} 255 \mathrm{X}$ & Impaired & 8 \\
\hline P4 & $10 \mathrm{yrs}$ & 11 months & $\begin{array}{r}\text { Classic } \\
\text { RTT }\end{array}$ & P152R & Impaired & 5 \\
\hline P5 & $11 \mathrm{yrs}$ & 11 months & $\begin{array}{r}\text { Classic } \\
\text { RTT }\end{array}$ & $\begin{array}{l}\text { del.exon } 4- \\
\quad 3\end{array}$ & $\begin{array}{l}\text { Never } \\
\text { Acquired }\end{array}$ & 8 \\
\hline P6 & $14 \mathrm{yrs}$ & 10 months & $\begin{array}{r}\text { Classic } \\
\text { RTT }\end{array}$ & P101L & Impaired & 9 \\
\hline \multicolumn{7}{|l|}{ Adults } \\
\hline P7 & $21 \mathrm{yrs}$ & 11 months & $\begin{array}{r}\text { Classic } \\
\text { RTT }\end{array}$ & $\mathrm{R} 306 \mathrm{C}$ & Impaired & 4 \\
\hline P8 & $23 \mathrm{yrs}$ & 11 months & $\begin{array}{r}\text { Classic } \\
\text { RTT }\end{array}$ & $\mathrm{R} 294 \mathrm{X}$ & Impaired & 6 \\
\hline P9 & $28 \mathrm{yrs}$ & 15 months & $\begin{array}{r}\text { Classic } \\
\text { RTT }\end{array}$ & R306C & $\begin{array}{l}\text { Walks } \\
\text { unsupport- } \\
\text { ed }\end{array}$ & 4 \\
\hline P10 & $32 \mathrm{yrs}$ & 13 months & $\begin{array}{r}\text { Classic } \\
\text { RTT }\end{array}$ & $\mathrm{R} 306 \mathrm{H}$ & Impaired & 6 \\
\hline
\end{tabular}

\footnotetext{
*As assessed by using the Vineland Adaptive Behavior Scales Survey Form
}

**The maximum score of 18 indicates the most severe phenotype 


\section{Measurement}

Information was collected on date of birth, diagnosis, genetic causation, early development and current status, the latter by completion of the Simplified Severity Score (Smeets et al. 2009) and the Vineland Adaptive Behavior Scale - Survey Form (Sparrow et al. 1984). The Simplified Severity Score addresses six features of RTT: sitting, walking, hand use, speech, epilepsy and spine deformation. Each domain is scored from 0 to 3 . The total score, which has a maximum of 18 , evaluates the overall severity of the syndrome. Scores of 9 or less are considered mild or less severe. The Vineland Adaptive Behavior Scale Survey Form contains 297 items, which assess adaptive behaviour in people with and without intellectual disabilities. Good internal consistency and inter rater reliability coefficients have been reported (Sparrow et al. 1984).

For the behavioural observation, categories were defined to cover the behaviour of the person with RTT, the social contact received from a parent or carer and the proximity of another person as an environmental condition. Behavioural categories and their definitions are set out in Table 3. In brief, the Engaged Activity category included any self-help, domestic activity/work, leisure/play or educational activity and included simple early years actions that may be appropriate for the person's developmental level, such as mouthing an object or manipulating a rattle or sensory toy. Engaged activity involving use of the hands was distinguished from that which did not involve the hands (e.g., looking at television or listening to a story). Social Engagement included all behaviours orientated towards another person to obtain and/ or maintain interaction, such as vocalizing towards another person, maintaining eye contact with a person, reaching out towards a person or orienting to a person in response to physical or vocal contact. Stereotypic behaviour, self-injury, aggression, breathing abnormalities and Rett episodes (a non-epileptic behaviour often misidentified as a possible seizure in which the eye gaze is not fixed, the person appears to be holding their breath, with absence of hand movements and motor activities) were defined, as was mood. Parent/carer interaction was defined as giving Support to assist the participant to conduct an activity or Help (i.e., attending to the participant to help them feed, drink, dress etc. but in a way that did not assist the participant to be involved in the activity). Other interactions were coded as positive, neutral or restraint. Parent/carer interaction categories were combined to form a single category, Adult Attention. Proximity of another person was defined as Alone (no-one else in the room), Not Close (another person in the room, but at least two metres away) or Close (another person in the room within two metres).

The observational data were captured on video using a digital camcorder in the participants' homes and, where relevant, schools or day placements. Arising from practical constraints, the number and length of recording sessions varied between participants. Total times ranged from $1 \mathrm{~h}$ and $28 \mathrm{~min}$ to $5 \mathrm{~h}$ and $30 \mathrm{~min}$, with an overall total across the 10 participants of $29 \mathrm{~h}$ and $8 \mathrm{~min}$. The aim was to record the participants' usual activities (e.g., leisure, meal time, group and individual activities). The person undertaking the recording tried to be as discrete as possible during the sessions so as not to intrude on the activities of the participants. Parents and carers/teachers were instructed to interact with the person as normal. On some occasions, observation had to be 
Table 3 Behavioural categories and operational definitions

Participant behaviour

Engaged Activity

Involving the use of hands Use of computer, switches, reaching for objects, manipulating toys or objects, taking objects to mouth, educational tasks, leisure, feeding, eating, self-help activity (for feeding, eating, self-help the person must be involved actively in the activity)

Not involving the use of hands

Social engagement

Eye contact

Vocalization

Movements

Disengaged

Disengaged

\section{RTT behaviours/mood}

Hand stereotypies

Other stereotypies

Self-injurious behaviours

Aggression

Mobility Mood

Breathing abnormalities Rett Episodes

Giving assistance (Support)
Listening to music, watching a DVD etc.

Looking at person for at least 3-5 s or more to attract, maintain or end interaction.

Any sound or word to attract, maintain or end interaction

Defined and clear movements to attract, maintain or end interaction

Passive or seemingly trivial movements, neither part of a constructive activity nor repetitive enough to constitute stereotypy nor sufficiently intense to constitute self-injury or aggression. Behaviour not directed towards any person or task.

Repetitive movements of the hands that include wringing, tapping, rubbing washing movements, hand mouthing. The movements may be performed with hands together or hands apart.

Includes any other repetitive movements such as body rocking, bruxism, repetitive movements with the head, repetitive tongue movements, facial grimacing and repetitive vocalisations.

Any behaviour that leads to physical harm or potential harm, including hitting own body, tapping/rubbing own body sufficiently to discolour skin, biting own body, scratching own body, hand biting, hair pulling, skin picking, banging own body (e.g., head) on fixtures (e.g., wall, table).

Any physical act towards another person that leads to physical harm or potential harm, includes behaviours such as hair pulling, hitting, breaking property or objects. Any vocal aggression, including screaming, shouting, swearing at another person.

Any behaviour when the child is moving around. Clear emotional states:

- Positive vocalization/facial expression: i.e. smiling, laughing

- Negative vocalization/facial expression: i.e. crying, screaming, sad expression.

Hyperventilation, breath hold, valsalva

Identified as possible seizure, eye glaze is not fixed, appear not to be breathing, no hand movements, absence of motor activities (non epileptic behaviour)

Parent or carer helps the person to do an activity by, verbal or physical prompting, giving an instructing, demonstrating or miming the activity or handing the person objects involved in the activity/ placing objects in front of the person or engaged in parallel play/activity (i.e. doing an activity alongside the person as an activity partner). May involve helping the person to feed or drink but, in general, does not involve doing an activity for the person (e.g., brushing hair, washing hands) 
Table 3 (continued)

Participant behaviour

Help

Positive interaction

Neutral Interaction

Restraint

Environmental condition

Alone

Not Close (person in the room)

Close (person in the room)
Doing an activity to/for the person that involves attention/contact such as feeding, dressing, washing, grooming the person in a way that does not encourage the person's involvement (i.e. his or her role is passive).

Parent or carer is interacting with the person in a positive manner but not in a way that gives assistance. i.e. praise, kissing/stroking the person, reading or singing to the person. The parent/carer must be involved with the person, giving attention.

Talking to the person in a way that neither encourages not discourages activity (e.g., greeting the person, incidental remarks, commenting). Or physically contacting the person in a way that neither encourages not discourages activity (e.g., holding hands, having the person sitting on lap).

- Prevention: Physical actions or vocalisations to discourage activity (e.g., physical prevention of movements, hold hand to stop stereotypies, telling the person not to do something).

- Mechanical restraint: for example the person is wearing an arm splint

Nobody in the room

Any person, family member or carer in the room but not close. Defined as being not within $2 \mathrm{~m}$.

Any person, family member or carer in the room and close. Defined as being within 1-2 $\mathrm{m}$.

stopped because the participant had a seizure, was not well or the presence of an extra person in the environment was too disruptive.

All videos were coded using OBSWIN software (Martin et al. 2001). Observation categories were allocated a key on the computer keyboard, which for convenience was labelled with an abbreviated category name. OBSWIN uses real time analyses in which all categories occur in temporal sequence measured by elapsed time in seconds from the beginning of the session. Times of occurrence correspond to key depressions. The variables under observation can be recorded as events (a single key depression which indicates occurrence during a particular one-second window) or as durations (two key depressions which indicate onset and offset times).

\section{Inter - Observer Reliability}

A second observer coded the first 15 min of each participant's observation session for inter-rater reliability, giving a total of $2.5 \mathrm{~h}$ checked for reliability ( $8.6 \%$ of the total). In comparing the timing of key depressions (onsets and offsets) between observers, those occurring within a tolerance of $5 \mathrm{~s}$ were considered agreements. Cohen's kappa was calculated for each variable under observation. However, as kappa becomes problematically stringent if a behaviour occurs very rarely or nearly all of the time, percentage occurrence agreement and percentage non occurrence agreement were also calculated.

Table 4 summarises mean Kappa values and occurrence and non occurrence agreement percentages across all variables under observation. Codes were divided into three categories: (a) reliably coded, with a kappa above 0.6 , (b) on the margins of being 
Table 4 Cohen's Kappa values and occurrence and non-occurrence agreement percentages for the observational categories

\begin{tabular}{|c|c|c|c|c|}
\hline & \multicolumn{2}{|l|}{ Kappa } & \multirow[t]{2}{*}{$\%$ Occurrence } & \multirow[t]{2}{*}{$\%$ Non Occurrence } \\
\hline & Mean & Range & & \\
\hline Engaged in activity (hands) & 0.74 & $0.68-1.00$ & 77.2 & 92.3 \\
\hline Engaged in activities (No hands) & 0.93 & $0.79-1.00$ & 91.3 & 99.4 \\
\hline Disengaged** & 0.59 & $0.00-1.00$ & 77.3 & 69.2 \\
\hline Eye contact & 0.58 & $0.00-0.88$ & 50.8 & 97.1 \\
\hline Vocalization & 0.63 & $0.35-0.92$ & 58.4 & 99.1 \\
\hline Movements & 0.92 & $0.92-0.92$ & 85.7 & 100.0 \\
\hline Hand stereotypies & 0.78 & $0.36-0.95$ & 88.1 & 74.8 \\
\hline Other stereotypies* & 0.40 & $0.12-0.79$ & 44.0 & 91.7 \\
\hline Self-injurious behaviours & 0.48 & $0.21-0.75$ & 37.5 & 99.3 \\
\hline Positive Mood* & 0.00 & NA & 0.0 & 99.1 \\
\hline Negative Mood & 1.00 & NA & 100.0 & 100 \\
\hline Breathing abnormalities** & 0.49 & $0.00-0.87$ & 62.3 & 83.7 \\
\hline Giving assistance (Support) & 0.82 & $0.45-1.00$ & 82.3 & 88.9 \\
\hline Help & 0.91 & $0.70-1.00$ & 90.4 & 97.1 \\
\hline Positive interactions & 0.51 & $0.00-1.00$ & 50.3 & 96.8 \\
\hline Neutral Interaction & 0.52 & $0.00-0.89$ & 46.4 & 94.0 \\
\hline Prevention* & 0.35 & $0.00-0.85$ & 28.0 & 97.8 \\
\hline Mechanical Restraint* & 0.00 & NA & 98.9 & 90.9 \\
\hline Alone & 0.86 & $0.76-0.96$ & 80.9 & 98.3 \\
\hline Not Close & 0.71 & $0.00-0.97$ & 66.0 & 98.9 \\
\hline Close & 0.87 & $0.74-1.00$ & 98.1 & 82.4 \\
\hline
\end{tabular}

*Codes excluded due to inadequate kappa

**Codes excluded due to inferior kappa and poor occurrence/non-occurrence reliability

reliably coded, with a kappa between 0.41 and 0.60 and (c) unreliably coded with kappa equal to or below 0.40 (see Landis and Koch (1977) for interpretation of kappa levels). Codes in the last category were excluded from analysis. For codes with a kappa of $0.41-0.60$, percentage occurrence and non occurrence agreement figures were examined to determine whether there could be reasonable confidence in the coding. Codes with a kappa in this range without occurrence or non-occurrence percentages above $90 \%$ were excluded from analysis. The aggression, mobility and Rett episodes categories were not observed during the reliability coding and were excluded from analysis.

\section{Data Analysis}

Percentage occurrence of each category was calculated by dividing its cumulative duration across bouts (onset times minus offset times) by the total session time. Variability in participants' levels of engagement in activity or social interaction together 
with the levels of adult attention each received was analysed in relation to participants' simplified severity scores and Vineland age equivalent scores using Spearman nonparametric correlation.

Variability of participant behaviour in relation to receipt of adult attention was analysed using lag analysis. The conditional probability of behaviour and attention occurring together was calculated by using a zero lag. In addition, the conditional probabilities of participant behaviour occurring up to $100 \mathrm{~s}$ before and after the onset of adult attention were calculated by grouping one second intervals into $10 \mathrm{~s}$ bins using a partial interval rationale and performing 10 lags in both directions. Conditional and unconditional probabilities were then used to calculate Yule's Q, a simple arithmetic transformation of the odds ratio (Yoder and Feurer 2000). The significance of Yule's Q was evaluated with the following equation (Sheskin 2003): $z=Q / \sqrt{ }\left[0.25\left(1-Q^{2}\right)^{2}(1 / a+\right.$ $1 / b+1 / c+1 / d)]$ where $a, b, c, d$ are cells of a typical $2 \times 2$ table. The alpha level for the lag analyses was reduced due to the number of tests performed: a $\mathrm{z}$ score above 3.09 $(p<.001)$ was considered as a significant level of association.

\section{Results}

\section{Percentage Occurrence of Behaviour and Environmental Conditions}

All participants were observed at home and six were also observed at school or day centre. Three of the five children and the adolescent wore arm splints for some of the time: P1, P2, P3 and P6. In general, participants were mainly in the company of parents, teachers or carers and received attention at a high rate (see Table 5). Parents were in close proximity for about two-thirds of the time at home (median $69.6 \%$, IQR $34.3 \%$, range $15.8 \%-90.2 \%$ ) and teachers or carers for even longer at school/day

Table 5 Percentage duration of time for each social environmental condition

\begin{tabular}{|c|c|c|c|c|c|c|c|c|}
\hline & \multicolumn{2}{|l|}{ Alone } & \multicolumn{2}{|c|}{ Not Close } & \multicolumn{2}{|l|}{ Close } & \multicolumn{2}{|c|}{ Adult Attention } \\
\hline & Home & School/Centre & Home & School/Centre & Home & School/Centre & Home & School/Centre \\
\hline \multicolumn{9}{|c|}{ Children and Adolescent } \\
\hline P1 & 13.1 & - & 13.1 & - & 73.7 & - & 35.5 & - \\
\hline P2 & 27.5 & 0.0 & 4.2 & 15.3 & 65.4 & 84.4 & 62.2 & 72.0 \\
\hline P3 & 0.8 & 0.0 & 0.0 & 9.1 & 97.5 & 90.8 & 82.0 & 89.4 \\
\hline P4 & 33.2 & 0.0 & 2.9 & 13.1 & 63.9 & 85.8 & 35.8 & 70.2 \\
\hline P5 & 0.3 & - & 0.7 & & 98.9 & - & 84.2 & - \\
\hline P6 & 18.5 & 0.0 & 17.3 & 3.4 & 64.2 & 96.2 & 55.4 & 92.4 \\
\hline \multicolumn{9}{|c|}{ Adults } \\
\hline P7 & 63.5 & 0.0 & 20.6 & 3.0 & 15.8 & 95.1 & 14.9 & 56.1 \\
\hline P8 & 9.9 & - & 28.0 & - & 61.9 & - & 39.2 & - \\
\hline P9 & 0.0 & 0.0 & 3.8 & 0.0 & 96.0 & 99.9 & 86.8 & 84.7 \\
\hline P10 & 0.0 & - & 1.4 & - & 98.4 & - & 82.0 & - \\
\hline
\end{tabular}


centre (median $93.2 \%$, IQR $11.7 \%$, range $84.4 \%$ - $99.9 \%$ ). Only one participant (P7) spent the majority of the time at home without close proximity $(84.1 \%)$. Participants also received adult attention for most of the time at home (median $58.8 \%$, IQR $46.3 \%$, range $14.9 \%-86.8 \%$ ) and at school (median $78.3 \%$, IQR $23.5 \%$, range $56.1 \%$ $92.4 \%$ ). Adult attention came in the form of Support to do an activity for a little over a tenth of the time at home (median $11.7 \%$, IQR $14.3 \%$, range $0.1 \%-36.8 \%$ ) and for about a third of the time at school (median $32.7 \%$, IQR $46.0 \%$, range $0.0 \%-70.0 \%$ ). There were no significant differences between child/adolescent and adult participants in these respects. Indeed, comparative median levels for these variables were rather similar.

The most common activities in which participants were engaged were: watching television, listening to music, listening to a story book and early learning activities involving simple manipulative toys, switches and water. The percentages of time that participants were engaged in constructive activities at home and at school/day centre are set out in Table 6 . Use of the hands at home occupied a median of $12.7 \%$ of the time (IQR $30.0 \%$, range $0.0 \%-54.1 \%$ ) and at school/day centre a median of $17.9 \%$ (IQR $40.8 \%$, range $2.5 \%-46.6 \%$ ). Four participants (P1, P3, P5 and P8) had zero or near zero constructive use of the hands. Engagement in activity involving the use of the hands was inversely related to the simplified severity score both at home and school/ day centre (Home: $\mathrm{r}_{\mathrm{s}}=-.64, p<.05$; School/Day centre: $\mathrm{r}_{\mathrm{s}}=-.93, p<.01$ ) and positively related to the Vineland motor skills age equivalent score at school/day centre $\left(\mathrm{r}_{\mathrm{s}}=.90, p<.05\right)$.

Engagement that did not involve the use of the hands occupied a median of $27.3 \%$ of the time at home (IQR $38.6 \%$, range $1.2 \%-85.7 \%$ ) and $16.0 \%$ of the time at school/day centre (IQR $33.4 \%$, range $4.2 \%-42.2 \%$ ). Such engagement was not related to either the severity score or Vineland equivalent age scores but was related at home to the level of adult attention $\left(\mathrm{r}_{\mathrm{s}}=.67, p<.05\right)$ and at school/day centre to the level of support (assistance/instruction) received from teacher or carer $\left(\mathrm{r}_{\mathrm{s}}=.89\right.$,

Table 6 Percentage durations of time participants were engaged in activity

\begin{tabular}{|c|c|c|c|c|c|c|}
\hline & \multicolumn{2}{|c|}{ Engaged Activity (hands) } & \multicolumn{2}{|c|}{ Engaged Activity (no hands) } & \multicolumn{2}{|c|}{ Social engagement } \\
\hline & Home & School/Centre & Home & School/Centre & Home & School/Centre \\
\hline \multicolumn{7}{|c|}{ Children and Adolescent } \\
\hline P1 & 0.8 & - & 1.2 & - & 1.9 & - \\
\hline $\mathrm{P} 2$ & 24.0 & 21.0 & 11.6 & 15.2 & 22.3 & 46.0 \\
\hline P3 & 0.0 & 4.8 & 46.7 & 4.2 & 10.0 & 15.1 \\
\hline P4 & 36.1 & 14.8 & 46.2 & 42.2 & 20.9 & 35.5 \\
\hline P5 & 0.0 & - & 85.7 & - & 11.3 & - \\
\hline P6 & 1.7 & 2.5 & 8.5 & 7.3 & 1.4 & 2.8 \\
\hline \multicolumn{7}{|c|}{ Adults } \\
\hline P7 & 54.1 & 46.6 & 13.9 & 16.8 & 6.1 & 13.5 \\
\hline P8 & 0.0 & - & 35.8 & - & 2.7 & - \\
\hline P9 & 23.6 & 44.5 & 57.8 & 39.2 & 12.5 & 7.1 \\
\hline P10 & 28.0 & - & 18.7 & - & 38.7 & - \\
\hline
\end{tabular}


$p<.05$ ). Engagement in activity either using or not using the hands, (median $46.7 \%$ of the time at home and $46.6 \%$ of the time at school or day centre) was inversely related to the simplified severity score at school/day centre $\left(\mathrm{r}_{\mathrm{s}}=-.93, p<.01\right)$, positively related to the Vineland motor skills age equivalent score at school/day centre $\left(\mathrm{r}_{\mathrm{s}}=.90\right.$, $p<.05$ ) and positively related to receipt of support in both settings (Home: $\mathrm{r}_{\mathrm{s}}=.65$, $p<.05 ;$ School/Day centre: $\mathrm{r}_{\mathrm{s}}=.87, p<.05$ ).

Social engagement occurred for a median of $10.7 \%$ of the time at home (IQR $18.7 \%$, range $1.4 \%-38.7 \%$ ) and a median of $14.3 \%$ of the time at school/day centre (IQR $32.1 \%$, range $2.8 \%-46.0 \%$ ) and was not related to either the severity score or Vineland equivalent age scores. At home it was positively related to the level of support received $\left(\mathrm{r}_{\mathrm{s}}=.79, p<.01\right)$. Only three participants $(\mathrm{P} 1, \mathrm{P} 6$ and $\mathrm{P} 8)$ were engaged in activity for the minority of the time. Social engagement levels were similar between child/adolescent and adult participants. There were no significant differences in the level of non-social engagement between child/adolescent and adult participants either but there was a tendency for levels of engagement using the hands to be higher among adult participants.

Table 7 summarises the percentages of time participants engaged in hand stereotypies and self-injury at home and in the school/day centre. Hand stereotypies observed included: hand wringing, hand flapping, hand mouthing, hand clapping and holding hands together. All but one participant (P9) were observed to engage in hand stereotypies for appreciable periods, although their extent for a third (P5) was less than for the remaining eight. There was no association between the extent of hand stereotypies and the simplified severity score or developmental age. Six participants were observed to self-injure (P1, P2, P5, P6, P8 and P9). Self-injurious behaviour observed included: biting the hand, biting the arm, biting the fingers, hitting the head with the fist and hitting the mouth. The extent of self-injury was not significantly associated with either the simplified severity score or developmental age.

Table 7 Percentage occurrence of hand stereotypies and self-injury

\begin{tabular}{|c|c|c|c|c|}
\hline \multirow[t]{2}{*}{ Participants } & \multicolumn{2}{|c|}{ Hand stereotypies } & \multicolumn{2}{|c|}{ Self-Injury } \\
\hline & Home & School/Centre & Home & School/Centre \\
\hline \multicolumn{5}{|c|}{ Children and Adolescent } \\
\hline P1 & 62.2 & - & 6.2 & - \\
\hline P2 & 71.2 & 22.9 & 1.9 & 1.7 \\
\hline P3 & 32.5 & 59.7 & 0.0 & 0.0 \\
\hline P4 & 99.4 & 89.8 & 0.0 & 0.0 \\
\hline P5 & 19.3 & - & 8.9 & - \\
\hline P6 & 61.2 & 54.1 & 6.0 & 1.5 \\
\hline \multicolumn{5}{|l|}{ Adults } \\
\hline P7 & 33.9 & 40.9 & 0.0 & 0.0 \\
\hline P8 & 94.6 & - & 2.8 & - \\
\hline P9 & 0.0 & 0.0 & 0.0 & 0.9 \\
\hline P10 & 54.5 & - & 0 & - \\
\hline
\end{tabular}




\section{Co-Occurrence of Behaviour and Adult Attention}

Six of the 15 Yule's Q scores between engagement using the hands and adult attention were significantly positive, two significantly negative and seven non-significant (see Table 8). Eight of the 15 Yule's Q scores between engagement not using the hands and adult attention were significantly positive, three significantly negative and four nonsignificant. Fourteen of the 16 Yule's Q scores between social engagement and adult attention were significantly positive and 2 non-significant. Four of the 14 Yule's Q scores between hand stereotypies and adult attention were significantly positive, five were significantly negative and five non-significant. Five of the seven Yule's Q scores between self-injury and adult attention were significantly negative, one significantly positive and one non-significant.

\section{Sequential Analysis}

Time based sequential analysis was conducted to calculate the conditional probability of the presence of the participants' engagement, hand stereotypies, and self-injury occurring prior to or after the onset of adult attention. There were 18 analyses relating to engagement in activity. In eight, no significant association with adult attention was found and in a further eight the conditional probability of engagement given attention was either consistently or fairly consistently either above or below the unconditional probability of engagement both before and after the onset of adult attention, again suggesting an absence of relationship. In the remaining two analyses, the conditional probability of engagement given attention was significantly reduced prior to receipt of attention and significantly increased afterwards, albeit only temporarily.

The 14 analyses of the relationship between hand stereotypies and adult attention showed either no or no consistent pattern. Self-injurious behaviours were observed in six participants, yielding seven sequential analyses. There was no interpretable pattern in three of these with the conditional probability of self-injury either being significantly below or above the unconditional probability both before and after the onset of adult attention. However, in the remaining four, there appeared to be a relationship between self-injury and receipt of adult attention (see Fig. 1). In three cases (P1 at home, P6 at school and P8 at home), there was evidence of the conditional probability being above the unconditional probability before the onset of attention and below it subsequently, suggesting a possible attention seeking motivation. In the fourth case (P2 at home), there was evidence of the conditional probability being below the unconditional probability before the onset of attention and above it subsequently, suggesting a possible avoidance motivation.

\section{Discussion}

Systematic observation was conducted to explore the frequency of various behaviours manifested by females with RTT and a confirmed MECP2 mutation. The behavioural observations were conducted in the participants' everyday environments with a view to analysing the relationship between adult proximity and attention and participants' behaviour. Although the study is to our knowledge the largest direct observational 
Table 8 Significant Yule's Q scores for the co-occurrence between levels of engagement, hand stereotypies and self-injury and receipt of adult attention

\begin{tabular}{|c|c|c|c|c|c|c|c|c|c|c|}
\hline \multirow[t]{2}{*}{ Participant } & \multicolumn{2}{|c|}{$\begin{array}{l}\text { Engaged in } \\
\text { activity (Hands) }\end{array}$} & \multicolumn{2}{|c|}{$\begin{array}{l}\text { Engaged in } \\
\text { activity (No } \\
\text { Hands) }\end{array}$} & \multicolumn{2}{|c|}{$\begin{array}{l}\text { Social } \\
\text { Engagement }\end{array}$} & \multicolumn{2}{|c|}{$\begin{array}{l}\text { Hand } \\
\text { stereotypies }\end{array}$} & \multicolumn{2}{|c|}{ Self-injury } \\
\hline & Home & $\begin{array}{l}\text { School/ } \\
\text { Centre }\end{array}$ & Home & $\begin{array}{l}\text { School/ } \\
\text { Centre }\end{array}$ & Home & $\begin{array}{l}\text { School/ } \\
\text { Centre }\end{array}$ & Home & $\begin{array}{l}\text { School/ } \\
\text { Centre }\end{array}$ & Home & $\begin{array}{l}\text { School/ } \\
\text { Centre }\end{array}$ \\
\hline \multicolumn{11}{|c|}{ Children and Adolescent } \\
\hline $\mathrm{P} 1$ & $\dagger$ & - & $*$ & - & $\begin{array}{l}+ \\
0 .- \\
91\end{array}$ & - & $\dagger$ & - & -0.69 & - \\
\hline $\mathrm{P} 2$ & $\begin{array}{l}+ \\
0 .- \\
44\end{array}$ & +0.39 & $\dagger$ & $\dagger$ & $\begin{array}{l}+ \\
0 .- \\
87\end{array}$ & +0.42 & -0.70 & -0.33 & $\dagger$ & -0.61 \\
\hline P3 & $\dagger$ & $\dagger$ & $\dagger$ & +1.00 & $\begin{array}{l}+ \\
0 .- \\
30\end{array}$ & +0.56 & -0.31 & $\dagger$ & - & - \\
\hline P4 & $\begin{array}{l}+ \\
0 .- \\
51\end{array}$ & +0.87 & -0.75 & +0.80 & $\begin{array}{l}+ \\
0 .- \\
80\end{array}$ & $\dagger$ & +1.00 & -0.48 & - & - \\
\hline P5 & $\dagger$ & - & -0.51 & - & $\begin{array}{l}+ \\
0 .- \\
83\end{array}$ & - & +0.93 & - & +0.88 & - \\
\hline P6 & $\begin{array}{l}+ \\
1 .- \\
00\end{array}$ & +1.00 & $\begin{array}{l}+ \\
0 .- \\
32\end{array}$ & +1.00 & $\begin{array}{l}+ \\
0 .- \\
96\end{array}$ & +1.00 & -0.50 & $\dagger$ & - & -0.92 \\
\hline \multicolumn{11}{|l|}{ Adults } \\
\hline P7 & $\dagger$ & -0.70 & $\begin{array}{l}+ \\
0 .- \\
33\end{array}$ & +0.77 & $\begin{array}{l}+ \\
0 .- \\
86\end{array}$ & +0.59 & $\dagger$ & +0.69 & - & - \\
\hline P8 & - & - & $\begin{array}{l}+ \\
0 .- \\
52\end{array}$ & - & $\begin{array}{l}+ \\
0 .- \\
63\end{array}$ & - & $\dagger$ & - & -0.44 & - \\
\hline P9 & $\dagger$ & $\dagger$ & $\dagger$ & -0.36 & $\begin{array}{l}+ \\
0 .- \\
97\end{array}$ & +0.42 & - & - & - & -0.40 \\
\hline $\mathrm{P} 10$ & -0.79 & - & $\begin{array}{l}+ \\
0 .- \\
90\end{array}$ & - & $\dagger$ & - & +0.51 & - & - & - \\
\hline
\end{tabular}

*The two behaviours did not occur together

$\dagger$ Non-significant association

study of females with RTT undertaken, it has a number of weaknesses. The sample included five children, one of whom had atypical RTT rather than classic RTT, an adolescent and four adults. The age range may be considered a weakness although there was broad similarity in the results between the children/adolescent and adults. The main difference was the suggestion that levels of engagement using the hands was higher among the adults. However, a larger sample is required to compare age groups 


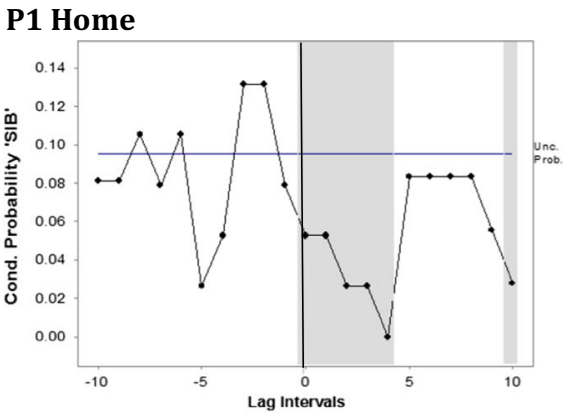

P8 Home

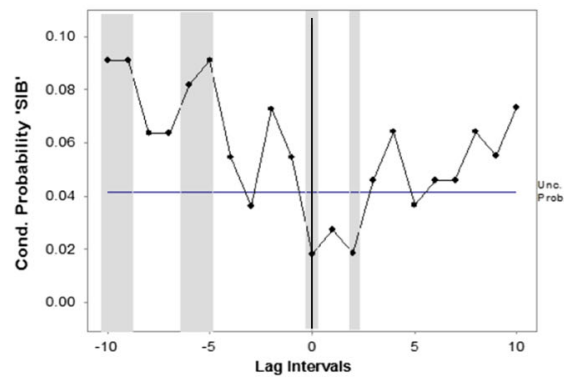

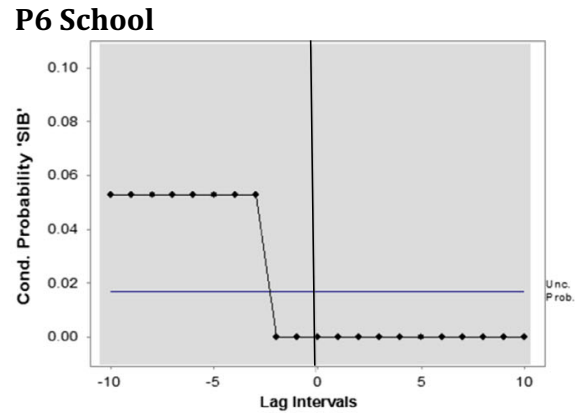

P2 Home

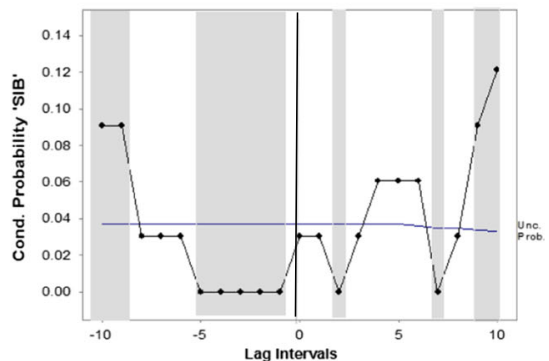

Fig. 1 Conditional probability of self-injurious behaviour (SIB) $100 \mathrm{~s}$ before and after the onset of adult attention and the unconditional probability of SIB** The horizontal line indicates the unconditional probability of SIB. The vertical line indicates the onset of adult attention. The dotted line indicates the conditional probability of SIB before and after the onset of adult attention. The shaded area indicates that the unconditional probability is significantly different from the conditional probability (absolute Yule's Q $>0.3$ )

adequately. Moreover, all participants had a milder severity score and, therefore, generalisation of the findings has to be limited. The extent of data collection per person and the activities represented within each participant's dataset were not standardised as practical constraints dictated that there was variation between participants. A subsequent study might ensure greater uniformity in these respects and have the capacity to analyse different types of activity period separately. Further development is also required to establish a definitive behavioural coding scheme with sufficiently good inter-observer agreement on all categories of interest. In addition, it is not known what effect filming as a means of data capture may have had on the events being recorded.

The one child with atypical RTT may be considered different to the remaining participants. She was also one of the two youngest participants. She had the highest severity score, which at nine was on the border of the transition from mild to severe, but she was cognitively the most able. She was the only participant to have some speech and she had the highest Vineland composite standard score and second highest developmental age, despite her youth. Like other participants, she spent most of her time in the company of a parent, teacher or carer but received the second lowest level of adult attention. Her level of engagement in constructive social or non-social activities was particularly low (less than $5 \%$ of the time). She spent about two-thirds of the time engaging in hand stereotypies, nearly three-fifths of the time in arm splints and was also one of the participants who self-injured. Her self-injury appeared to be attention- 
seeking. It occurred significantly less often when she was receiving adult attention and the lag analysis also suggested an attention-seeking motivation.

Compared to data from residential settings for individuals with a similar severity of intellectual disability (e.g., Emerson et al. 1999, 2000), individuals with classic RTT in this study received a high level of adult attention in the form of positive interaction, assistance or help. In addition, their levels of social interaction and engagement in activities were also relatively high. Clearly, one cannot make comparisons between different types of environment without taking account of contextual factors such as the ratio between those needing support and those in support roles. However, the above comparisons do seem to indicate that the classic RTT participants in this sample had a relatively rich social environment. After the regression stage, individuals with RTT are reported to be sociable and to be responsive to their environment. Such characteristics may help sustain a conducive social environment.

Engagement in activity has been much studied in residential settings and there is fairly consistent evidence that there is a primary association with individual ability as measured by an adaptive behaviour scale and a secondary association with care practices, as measured by the extent of practical support individuals receive or the implementation of 'active support' (Felce and Perry 1995; Felce and Emerson 2001; Felce et al. 2003; Mansell et al. 2003; Perry and Felce 2005). Findings here were consistent with this evidence to some extent. Engagement in activity using the hands was associated with a less severe condition and greater adaptive behaviour, engagement in activity not using the hands occurred most commonly with receipt of adult attention among the majority of participants, and engagement in activity whether using the hands or not and social engagement were associated with receipt of support. However, a relationship between non-social engagement in activity and receipt of attention was not demonstrated in the sequential lag analyses.

Stereotyped hand movements are considered to be characteristic features of RTT and among the essential diagnostic criteria. Despite this, the duration of hand stereotypies observed varied across the sample, from a very limited extent to almost all of the time. Variation appeared to be independent of social context. The correlation between the extents of hand stereotypies and adult attention was insignificant and there were no consistent associations between hand stereotypies and adult attention revealed in the concurrent or sequential lag analyses. This apparent independence from environmental influence is consistent with the findings of Wales et al. (2004) who demonstrated that the hand stereotypies of eight girls with RTT were not susceptible to environmental manipulation.

Self-injury is not an essential diagnostic criterion for RTT but has been shown to occur in a reasonably high proportion. Self-injury was found to occur more frequently among individuals with a severity score in the mild range among the national sample from which this sample was drawn (Cianfaglione et al. 2015a). This may explain why as many as six (five with classic RTT and one atypical RTT) out of the ten participants in this study were observed to self-injure. As in Oliver at al. (1993) there was evidence that self-injury may be socially motivated.

Despite the inconsistency of results across participants, the study has highlighted the importance of considering the role of the environment in shaping the behaviour of females with RTT. The participants in this study appeared to experience a carer and attention rich environment and their levels of engagement were likely to be higher than 
in some other studies as a result. As in the more general literature, engagement in activity was related to personal development and to social support. Hand stereotypies are characteristic, although varying considerably across participants, and appear unrelated to environmental events. Self-injury in RTT appears to occur for reasons similar to that in other individuals with intellectual disability. It was found to be associated with overactivity and impulsivity (Cianfaglione et al. 2015a) and may serve attention-seeking or social avoidance purposes.

Acknowledgments This project was funded by the NISCHR Social Care Studentship scheme. We would like to thank the families and individuals who agreed to take part and the Rett UK for their support of the study and the BIRSS database.

Author Contributions RC conducted the study and wrote the first draft as part of her PhD research. AM undertook observation for reliability purposes. AC, MK and RH were academic supervisors or mentors to RC and have commented on the manuscript, DF conceived the study, was the main supervisor of RC and coordinated the writing of the manuscript.

\section{Compliance with Ethical Standards}

Role of the Funding Source NISCHR had no involvement in the writing of this paper or the decision to submit the paper for publication.

Ethical Approval Ethical approval was provided by the NHS Research Ethics Committee for Wales, Cardiff, Wales, UK. All procedures performed in studies involving human participants were in accordance with the ethical standards of the institutional and/or national research committee and with the 1964 Helsinki declaration and its later amendments or comparable ethical standards.

Informed Consent Parents gave informed consent for their children and assent for their adult offspring.

Conflict of Interest The authors declare no conflict of interests.

Open Access This article is distributed under the terms of the Creative Commons Attribution 4.0 International License (http://creativecommons.org/licenses/by/4.0/), which permits unrestricted use, distribution, and reproduction in any medium, provided you give appropriate credit to the original author(s) and the source, provide a link to the Creative Commons license, and indicate if changes were made.

\section{References}

Amir, R. E., Veyver, I. B., Wan, M., Tran, C. Q., Franckle, U., \& Zoghbi, H. Y. (1999). Rett syndrome is caused by mutations in X-linked MECP2, encoding methyl-CpG - binding protein 2. Nature Genetics, 23, 185-187.

Cass, H., Reilly, S., Owen, L., Wisbeach, A., Weekes, L., Slonims, V., et al. (2003). Findings from a multidisciplinary clinical case series of females with rett syndrome. Developmental Medicine and Child Neurology, 45, 325-337.

Cianfaglione, R., Clarke, A., Kerr, M., Hastings, R. P., Oliver, C., Moss, J., et al. (2015a). A national survey of rett syndrome: behavioural characteristics. Journal of Neurodevelopmental Disorders, 7, 11.

Cianfaglione, R., Clarke, A., Kerr, M., Hastings, R. P., Oliver, C., \& Felce, D. (2015b). A national survey of Rett syndrome: Age, clinical characteristics, current abilities and health. American Journal of Medical Genetics Part A, 167a, 1493-1500.

Coleman, M., Brubaker, J., Hunter, K., \& Smith, G. (1988). Rett syndrome: A survey of North American patients. Journal of Mental Deficiency Research, 32, 117-124. 
Emerson, E., Hatton, C., Robertson, J., Henderson, D., \& Cooper, J. A. (1999). Descriptive analysis of the relationships between social context, engagement and stereotypy in residential services for people with severe and complex disabilities. Journal of Applied Research in Intellectual Disabilities, 12, 11-29.

Emerson, E., Robertson, J., Gregory, N., Kessissoglou, S., Hatton, C., Hallam, A., et al. (2000). The quality and costs of community-based residential supports and residential campuses for people with severe and complex disabilities. Journal of Intellectual and Developmental Disability, 25, 263-279.

Felce, D., \& Emerson, E. (2001). Living with support in a home in the community: predictors of behavioral development and household and community activity. Mental Retardation and Developmental Disabilities Research Reviews, 7, 75-83.

Felce, D., \& Perry, J. (1995). The extent of support for ordinary living provided in staffed housing: the relationship between staffing levels, resident dependency, staff:resident interactions and resident activity patterns. Social Science and Medicine, 40, 799-810.

Felce, D., Jones, E., Lowe, K., \& Perry, J. (2003). Rational resourcing and productivity: relationships among staff input, resident characteristics and group home quality. American Journal on Mental Retardation, $108,161-172$.

Halbach, N. S., Smeets, E. E., Schrander-Stumpel, C. T., Van Schrojenstein Lantman De Valk, H. H., Maaskant, M. A., \& Curfs, L. M. (2008). Aging in people with specific genetic syndromes: Rett syndrome. American Journal of Medical Genetics Part A, 146a, 1925-132..

Iwata, B. A., Pace, G. M., Willis, K. D., Gramache, T. B., \& Hyman, S. L. (1986). Operant studies of selfinjurious hand biting in the rett syndrome. American Journal of Medical Genetics, 25. Supplement, 1, $157-166$.

Landis, J. R., \& Koch, G. G. (1977). The measurement of observer agreement for categorical data. Biometrics, $33,159-174$.

Mansell, J., Beadle-Brown, J., Macdonald, S., \& Ashman, B. (2003). Resident involvement in activity in small community homes for people with learning disabilities. Journal of Applied Research in Intellectual Disabilities, 16, 63-74.

Martin, N., Oliver, C., \& Hall, S. (2001). OBSWIN: Software for the collection and analysis of observational data. Birmingham UK: Cerebra Centre for Neurodevelopmental Disorders, University of Birmingham.

Mount, R. H., Hastings, R. P., Reilly, S., Cass, H., \& Charman, T. (2001). Behavioural and emotional features in rett syndrome. Disability Rehabilitation, 23, 129-138.

Mount, R. H., Hastings, R. P., Reilly, S., Cass, H., \& Charman, T. (2003). Towards a behavioral phenotype for rett syndrome. American Journal on Mental Retardation, 108, 1-12.

Neul, J. L., Kaufmann, W., Glaze, D. G., Christodoulou, J., Clarke, A. J., Bahi-Buisson, N., et al. (2010). Rett syndrome: revised diagnostic criteria and nomenclature. Annals of Neurology, 68, 944-950.

Oliver, C., Murphy, G. H., Crayton, L., \& Corbett, J. A. (1993). Self-injurious behavior in rett syndrome: interactions between features of rett syndrome and operant conditioning. Journal of Autism and Developmental Disorders, 23, 91-109.

Perry, J., \& Felce, D. (2005). Predictors of outcome in community group homes. American Journal on Mental Retardation, 110, 121-135.

Roane, H., Piazza, C., Sgro, G., Volkert, V., \& Anderson, C. (2001). Analysis of aberrant behaviour associated with rett syndrome. Disability and Rehabilitation, 23, 139-148.

Sansom, D., Krishnan, V., Corbett, J., \& Kerr, A. (1993). Emotional and behavioural aspects of rett syndrome. Developmental Medicine and Child Neurology, 35, 340-345.

Sheskin, D. J. (2003). Handbook Of parametric and nonparametric statistic procedures. Boca Raton: Chapman and Hall.

Smeets, E. E. J., Chenault, M., Curfs, L. M. G., Schrander-Stumpel, C. T. R. M., \& Frijns, J. P. (2009). Rett syndrome and long-term disorder profile. American Journal of Medical Genetics Part A, 149a, 199205 s.

Sparrow, S.S., Balla, D., \& Cicchetti, D.V. (1984). Vineland Adaptive Behavior Scales (Survey Ed.). Circle Pines, MN, USA: American Guidance Service.

Wales, L., Charman, T., \& Mount, R. (2004). An analogue assessment of repetitive hand behaviours in girls and young women with rett syndrome. Journal of Intellectual Disability Research, 48, 672-678.

Wehmeyer, M., Bourland, G., \& Ingram, D. (1993). An analogue assessment of hand stereotypies in two cases of rett syndrome. Journal of Intellectual Disability Research, 37, 95-102.

Yoder, P. J., \& Feurer, I. D. (2000). Quantifying the magnitude of sequential association between events or behaviors. In T. Thompson, D. Felce, \& F. Symons (Eds.), Behavioral observation: Technology and application in developmental disabilities (pp. 317-333). Baltimore: Brookes. 